\title{
Editorial
}

\section{1: Ano internacional para a eliminação do trabalho infantil}

doi: 10.1590/\$1679-49742021000100001

\author{
2021: International Year for the Elimination of Child Labour \\ 2021: Año Internacional de la Erradicación del Trabajo Infantil
}

$\mathrm{E}$ m 2017, a Assembleia Geral das Nações Unidas adotou, por unanimidade, a resolução que declarou 2021 como o "Ano Internacional para a Eliminação do Trabalho Infantil". ${ }^{1}$ Tal resolução se alinha com a Agenda para o Desenvolvimento Sustentável (2015-2030), que reconhece a pobreza extrema como o maior desafio global e sua erradicação como requisito indispensável para o alcance do desenvolvimento sustentável, em suas três dimensões - econômica, social e ambiental -, e compreende um conjunto de objetivos e metas abrangentes e transformadoras. A meta 8.7 estabelece o compromisso de erradicar todas as formas de trabalho infantil até $2025 .{ }^{2}$

0 trabalho infantil é qualquer forma de trabalho que priva as crianças de sua infância, de seus potenciais e dignidade, e prejudica seu desenvolvimento físico e mental. A Organização Internacional do Trabalho (OIT) considera crianças os menores de 18 anos de idade, e elenca quatro categorias de piores formas de trabalho infantil (Figura 1). ${ }^{3}$

\begin{tabular}{|c|c|}
\hline & $\begin{array}{l}\text { a) todas as formas de escravidão ou práticas análogas à escravidão, tais como a venda e tráfico de crianças, a servidão por dívidas e a } \\
\text { condição de servo, e o trabalho forçado ou obrigatório, inclusive o recrutamento forçado ou obrigatório de crianças para serem utilizadas } \\
\text { em conflitos armados; }\end{array}$ \\
\hline & b) a utilização, o recrutamento ou a oferta de crianças para a prostituiç̧ão, a produção de pornografia ou atuações pornográficas; \\
\hline & $\begin{array}{l}\text { c) a utilização, recrutamento ou a oferta de crianças para a realização de atividades ilícitas, em particular a produção e o tráfico de } \\
\text { entorpecentes, tais como definidos nos tratados internacionais pertinentes; e }\end{array}$ \\
\hline 4 & $\begin{array}{l}\text { d) } 0 \text { trabalho que, por sua natureza ou pelas condições em que é realizado, é suscetível de prejudicar a saúde, a segurança ou a moral } \\
\text { das crianças. }\end{array}$ \\
\hline
\end{tabular}

Figura 1 - Piores formas de trabalho infantil, conforme a Organização Internacional do Trabalho

A definição de trabalho infantil varia conforme os marcos legais de cada país. No Brasil, as atividades laborais são proibidas até os 13 anos de idade. A partir dos 14, até os 24 anos de idade, é permitida a contratação como aprendiz. ${ }^{4,5}$ Adolescentes de 16 e 17 anos de idade têm permissão para trabalhar, desde que não realizem atividades noturnas, insalubres, perigosas, ou penosas, constantes na lista nacional das piores formas de trabalho infantil. ${ }^{6}$

No mundo, segundo a OIT, havia 152 milhões de crianças trabalhando, em 2016, com maior prevalência na África (19,6\%), seguida pelas Américas (5,3\%). ${ }^{7}$ No Brasil, de acordo com resultados da Pesquisa Nacional por Amostra de Domicílios (PNAD) Contínua - Trabalho das Crianças e Adolescentes, realizada pelo Instituto Brasileiro de Geografia e Estatística (IBGE), em 2019, havia 1,8 milhão de crianças e adolescentes com idade entre 5 e 17 anos em situação de trabalho infantil, dos quais 706 mil estavam ocupados nas piores formas de trabalho infantil. Do total da população em trabalho infantil, 53,7\% tinham de 16 a 17 anos, 25,0\% tinham de 14 a 15 anos e 21,3\% tinham de 5 a 13 anos de idade. A maior parte era do sexo masculino $(66,4 \%)$ e de cor preta ou parda $(66,1 \%) .{ }^{8}$ 
De 2016 a 2019, a prevalência do trabalho infantil declinou de 5,3\% para 4,6\% no país. ${ }^{8}$ Contudo, o trabalho infantil permanece como um dos mais graves problemas do Brasil, e a tendência de declínio pode ser interrompida a partir da emergência da COVID-19. A interrupção das atividades escolares, em decorrência das medidas de distanciamento necessárias ao enfrentamento da pandemia, e o aumento da pobreza, são fatores que contribuem para 0 crescimento do trabalho infantil. Organismos internacionais, como a OIT e o Fundo das Nações unidas para a Infância (Unicef) têm alertado para esta situação. ${ }^{9}$

A vigilância em saúde tem um papel importante no enfrentamento do trabalho infantil. Sistemas de vigilância que fornecem informações sobre o perfil das crianças e adolescentes em situação de trabalho, onde se encontram, assim como os tipos de lesões e doenças que ocorrem nessa população, são essenciais para direcionar e avaliar os esforços de prevenção.$^{10}$ Para tanto, é necessário aprimorar os sistemas de informação em saúde nacionais, a fim de que tenham cobertura, qualidade e oportunidade adequadas para notificação dos agravos relacionados ao trabalho infantil, incluindo acidentes, violências e óbitos.

Com 0 intuito de chamar a atenção para o problema e destacar o Ano Internacional para a Eliminação do Trabalho Infantil, a Epidemiologia e Serviços de Saúde: revista do Sistema Único de Saúde do Brasil exibe, em sua capa do volume 30 (2021), as cores de uma das pás do cata-vento, símbolo da luta pela erradicação do trabalho infantil no mundo.

Leila Posenato Garcia' - (1) orcid.org/0000-0003-1146-2641

Taís Freire Galvão² - @ orcid.org/0000-0003-2072-4834

'Fundação Jorge Duprat Figueiredo de Segurança e Medicina do Trabalho, Centro Regional Sul, Florianópolis, SC, Brasil ${ }^{2}$ Universidade Estadual de Campinas, Faculdade de Ciências Farmacêuticas, Campinas, SP, Brasil

\section{Referências}

1. United Nations. International Year for the Elimination of Children Labour. [New York]: UN; 31 jul. 2019 [acesso 03 mar. 2021]. Disponível em: http://digitallibrary.un.org/record/3814287

2. United Nations. Transforming our world: the 2030 Agenda for Sustainable Development [Internet]. [New York]: UN; 2015 [acesso 3 mar. 2021]. Disponível em: https://www.un.org/ga/search/view_doc.asp?symbol=A/RES/70/1\&Lang=E

3. International Labour Organization. Convention concerning the prohibition and immediate action for the elimination of the worst forms of child labour [Internet]. [Geneva]: IL0; 1999 Jun 17 [acesso 3 mar. 2021]. Disponível em: https://www. un.org/en/development/desa/population/migration/generalassembly/docs/globalcompact/ILO_C_182.pdf

4. Brasil. Lei n. 10.097, de 19 de dezembro de 2000. Altera dispositivos da Consolidação das Leis do Trabalho - CLT, aprovada pelo Decreto-Lei no 5.452, de 10 de maio de 1943. Brasília, DF: Diário Oficial da União; 20 dez. 2000 [acesso 3 mar. 2021]. Disponível em: https://www.planalto.gov.br/ccivil_03/leis/110097.htm/Decreto 9579/2018

5. Brasil. Decreto n. 9.579, de 22 de novembro de 2018. Consolida atos normativos editados pelo Poder Executivo federal que dispõem sobre a temática do lactente, da criança e do adolescente e do aprendiz, e sobre o Conselho Nacional dos Direitos da Criança e do Adolescente, o Fundo Nacional para a Criança e o Adolescente e os programas federais da criança e do adolescente, e dá outras providências. Brasília, DF: Diário Oficial da União; 23 nov. 2018 [acesso 3 mar. 2021]. Disponível em: http://www.planalto.gov.br/ccivil_03/_Ato2015-2018/2018/Decreto/D9579.htm\#art126

6. Brasil. Decreto n. 6.481, de 12 de junho de 2008. Regulamenta os artigos 30, alínea "d”, e 40 da Convenção 182 da Organização Internacional do Trabalho (OIT) que trata da proibição das piores formas de trabalho infantil e ação imediata para sua eliminação, aprovada pelo Decreto Legislativo no 178, de 14 de dezembro de 1999, e promulgada pelo Decreto n. 3.597, de 12 de setembro de 2000, e dá outras providências. Brasília, DF: Diário Oficial da União; 13 jun. 2008, retif. 23 out. 2008 [acesso 3 mar. 2021]. Disponível em: http://www.planalto.gov.br/ccivil_03/_ato20072010/2008/decreto/d6481.htm 
7. International Labour Office. Global estimates of child labour: results and trends, 2012-2016. Geneva: ILO; 2017 [acesso 3 mar. 2021]. Disponível em: https://www.ilo.org/wcmsp5/groups/public/@dgreports/@dcomm/documents/publication/ wcms_575499.pdf

8. Instituto Brasileiro de Geografia e Estatística. Trabalho de crianças e adolescentes de 5 a 17 anos de idade: 2016-2019: PNAD-contínua. [Rio de Janeiro]: IBGE; 2020 [ acesso 3 mar. 2021]. Disponível em: https://biblioteca.ibge.gov.br/ visualizacao/livros/iv101777_informativo.pdf

9. UNICEF Data. COVID-19 and Child Labour: a time of crisis, a time to act [Internet]. [Geneva]: UNICEF; Jun 2020 [acesso 3 mar. 2021]. Disponivel em: https://data.unicef.org/resources/covid-19-and-child-labour-a-time-of-crisis-a-time-to-act/

10. Wegmann D. Child labor in the US. Cienc Saude Colet. 2003;8(4):1029-37. https://doi.org/10.1590/ S1413-81232003000400024. https://www.scielo.br/scielo.php?script=sci_arttext\&pid=S141381232003000400024\#: :text=Although\%20some\%20states\%20have\%20enacted,to\%2054\%20hours\%20per\%20week 